\title{
The Application of Multisim Simulation Platform in Teaching and Scientific Research of Mixed-signal Circuit
}

\author{
Jiebin $\mathrm{Su}$ \\ Department of electronic engineering \\ Xiamen University \\ Xiamen, China
}

\begin{abstract}
The outstanding features and powerful function of Multisim software are illustrated in this paper through introducing application of Multisim simulation platform in teaching which has provided a simulation platform for mixed circuit teaching and has been applied by teachers in mixed circuit teaching to spread circuit knowledge and enhance innovation ability of students. However, there are some problems which should be improved, such as the error from experimental components and changeable experimental environment, the error range of simulation components should be modified to close to the actual value. In new era, the relationship between them has been studied deeply in this paper, summed up the reasons of success and lessons learned, of which influence and enlightenment is conducive to positive interaction between them.
\end{abstract}

Keywords-Multisim; Digital-analog hybrid circuit; teaching; research; application

\section{Digital-ANALOG HYBRID CIRCUIT TEACHING AND MULTISIM SIMULATION PLATFORM}

Digital-analog hybird circuit teaching refers to integration of digital circuit and analog circuit in circuit teaching, rather than separately studying digital circuit or analog circuit. At present, the teaching mode is applied in most colleges that students majoring electronic information start to study digital circuit course from second grade and study analog circuit from third grade, which is benefit to make foundation of digital circuit and analog circuit respectively. However, with the development of electronic information industry, hybird circuit design ability has become a basic requirement for electronic circuit students. As everyone knows, since analog circuit is used to deal with the continuous signal, while digital circuit is used for data processing and signal control, integration of analog circuit and digital circuit can make good circuit design, and enhance comprehensive ability of students. Therefore, in electronic circuit teaching and research, digitalanalog hybird circuit teaching has become more and more necessary.

Multisim software is a circuit function simulation platform developed by NATIONAL INSTRUMENTS. Because of the distinctive features and powerful functions, it has been becoming very popular in students majoring electronic. Specifically, it contains rich components library and common discrete electronic components required by analog circuit, such as resistors, capacitors, inductors, power supply modules, signal generation modules and switching transistors, and virtual instruments required for measurement of simulation results, such as multi-channel Agilent oscilloscope, digital oscilloscope, Multi-meter which provide students with great convenience for analog circuit design, simulation and experimental observation. In addition, the common modules components library of Multisim such as various logic gates, counters, CPLD/FPGA, microcontroller and so on can be used to design logic circuits. Undoubtedly, it is of great help for students to understand the logic of digital circuits. In addition, Multisim also contains a digital / analog converter, analog / digital converter, motor driver, motor model, switching power supply devices and other functional modules which can be used to design Power Electronical Circuit conveniently.

In digital-analog hybrid circuit teaching, since complicacy of circuit, making actual circuits will take high cost and more time, therefore, making simulation will improve teaching efficiency. However, most simulation platforms can only simulate single analog circuit or digital circuit, as mentioned above, Mutisim simulation platform can simulate both digital circuit and analog circuit, and can be combined with digitalanalog hybrid circuit teaching mode.

\section{ThE SPECIFIC WAYS AND EFFECTS OF USING MULTISIM Simulation PlatForm By COLLEGE TEACHERS}

As mentioned above, in digital-analog hybrid circuit teaching, taking functional simulation is necessary. Since Multisim software can simulate analog circuit and digital circuit simulation, it is often used in digital-analog hybrid circuit teaching.

For example, Experiment 1 "Fig. 1": it is well known that buck-type switching power supply circuit is a typical digitalanalog hybrid circuit. PWM (Pulse Width modulation) signal can be generated by digital circuit. According to switching power principle, when the PWM module makes high level voltage to the switch, switch turn on, the current of inductor will rise; while the PWM module makes low level voltage to the switch, switch turn off, the current of inductor will reduce. 
Therefore, the current of inductor can be controlled by switching period. ${ }^{[1]}$

By Ohm's Law (formula (1) ${ }^{[2]}$ ), the voltage value Vout measured by oscilloscope is equal to the current value I of inductor. The formula (2) (3) (4) ${ }^{[3]}$ can be obtained by switching power supply principle, where Ton is the duration time of high level in period $\mathrm{T}$, Toff is the duration time of low level. Thus Vout is proportional to the duty ratio of PWM, under the situation of constant period $\mathrm{T}$, the more Ton, the more the average current of inductor.

$$
\text { Vout }=\mathrm{I} * \mathrm{R}
$$

$$
\begin{aligned}
& \text { Vout }=\text { VDC } * \text { Ton } /(\text { Ton }+ \text { Toff }) \\
& \mathbf{T}=\text { Ton }+ \text { Toff } \\
& \text { Duty_ratio }=\text { Ton } /(\text { Ton }+ \text { Toff })
\end{aligned}
$$

In experiment, set switching frequency $\mathrm{f}=1 / \mathrm{T}=30 \mathrm{KHZ}$, Duty_ratio respectively of $25 \%, 50 \%, 75 \%$, the theoretical voltage value calculated are respectively $2.5 \mathrm{~V}, 5.0 \mathrm{~V}, 7.5 \mathrm{~V}$. While the simulation results by Multisim measured by virtual oscilloscope are respectively $2.48 \mathrm{~V}, 4.95 \mathrm{~V}, 7.43 \mathrm{~V}$, which achieved the expected results.

\section{SWITCH}

Inductor

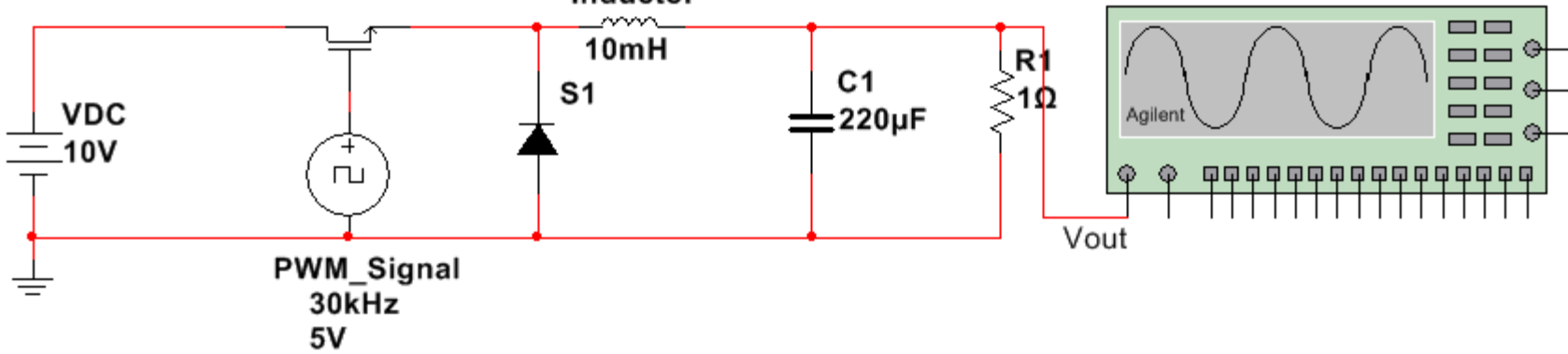

Fig. 1. Typical buck-type Switching Power Supply. ${ }^{[4]}$

\section{Experiment 2:}

In electronic engineering teaching, the control circuit of motor is a typical digital-analog hybrid circuit, of which the key is to control current of inductor of the motor.

As shown in "Fig. 2", switching transistors S1, S2, S3, $\mathrm{S} 4$ which form a $\mathrm{H}$ Bridge circuit are controlled by a digital circuit made up of logic gates U1, U2, U3, U4. When the circuit works normally, a set of switching transistors located in diagonal turn on; while a set of switching transistors in another diagonal turn off. When S1, S3 switching on and S2, S4 turning off, the current loop is VDC-S1-Inductor-S3-R1Ground, in which R1 is the sampling resistor of the circuit; when S2, S4 switching on and S1, S3 turning off, the current loop is VDC-S2-Inductor-S4-R1-Ground. Combinational logic made up by U1, U2, U3, U4 can ensure that S1, S3 switching on and S2, S4 turning off, while S2, S4 switching on and S1, S3 turning off, as well as S1 and S4 will not switch on at same time, also S2 and S3 will not switch on at same time (if the switches at the same side turn on at the same time, great short-circuit current will be generated and the circuit will be burn out). When Control signal is at high level, PWM signal control S1, S3; When Control is low, the PWM signal control S2, S4. In this example, we set the Control at high level. As mentioned in experiment 1 , the voltage value measured by oscilloscope is equal to the current value of inductor, and the current value is proportional to Duty_ratio of PWM signal. Setting Duty_ratio as $25 \%, 50 \%, 75 \%$, respectively, the theoretical voltage value can be calculated as $2.5 \mathrm{~V}, 5.0 \mathrm{~V}, 7.5 \mathrm{~V}$ respectively. The measured values by Multisim oscilloscope is $2.45 \mathrm{~V}, 4.9 \mathrm{~V}, 7.35 \mathrm{~V}$ which have small error with actual values, in line with the experimental results, that is, the motor current can be changed through changing Duty_ration of PWM signal [5]. 


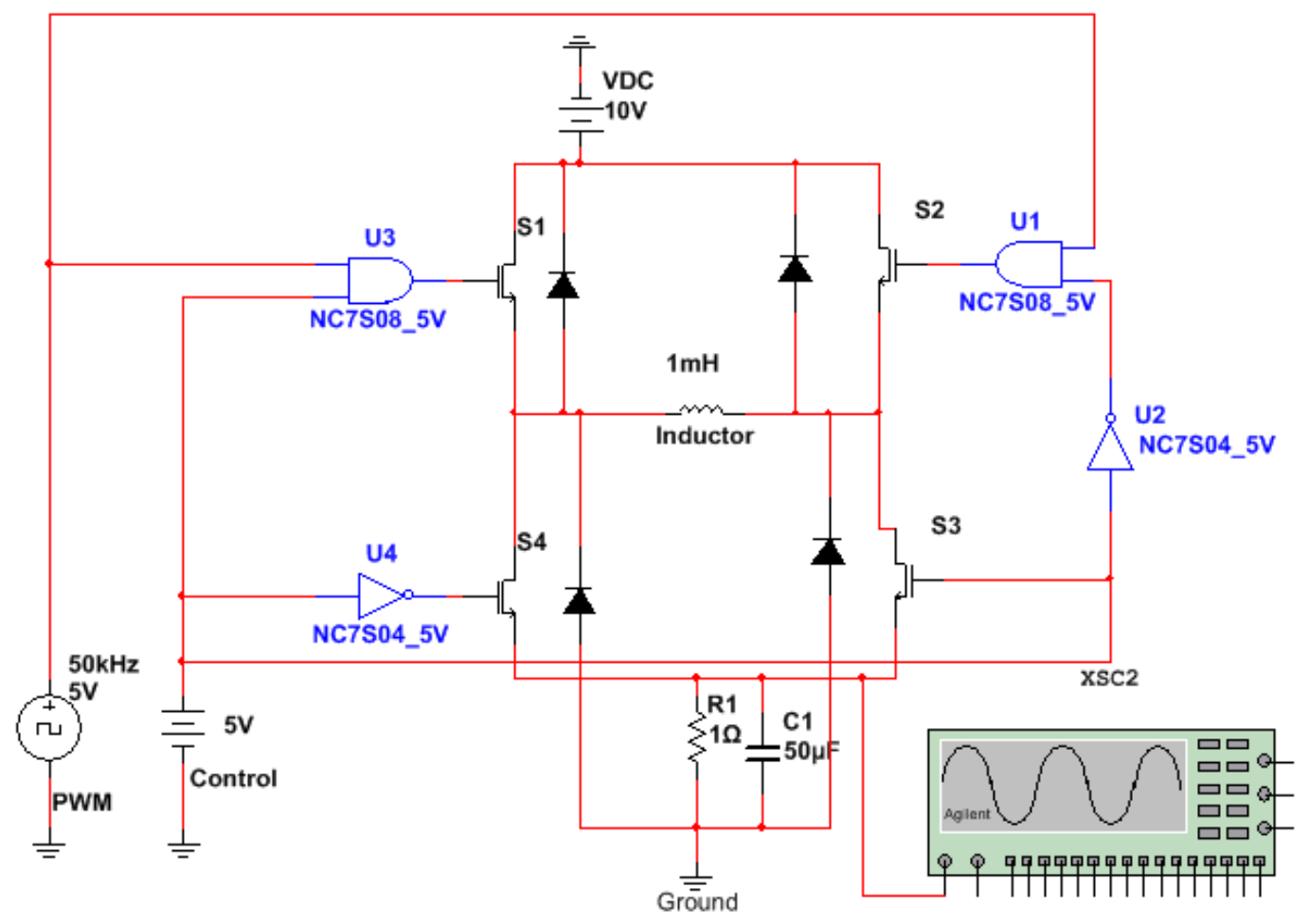

Fig. 2. PWM Motor Driver Circuit.

\section{Experiment 3:}

Base on Experiment 2, we now control motor current through pulse frequency modulation (PFM), that is, frequency converting control current. As shown in formula (3) and (4) in Experiment 1, making Ton constant and Toff changing can achieve frequency change and Duty_ratio change.

The schematic diagram was designed as shown in "Fig. 3", in which, PFM module generates a fixed conduction time (Ton) ${ }^{[6]}$, voltage value Vout measured by sampling resistor is compared with set voltage value Vref, the combination digital logic circuit of output signal from comparator combines, control signal and PFM module management switches S1, S2, $\mathrm{S} 3, \mathrm{~S} 4$ conduction and turn off, the DAC module can control the value of Vref, thus a circuit diagram was designed as shown in "Fig. 4" in which we get the following formula:

$$
\mathrm{f}=\text { Vout } /(\text { VDC } * \text { Ton })
$$

As shown in formula (5), Switching frequency $f$ is proportional to Vout. As mentioned in Experiment 2, the voltage value measured by oscilloscope is equal to the current value of inductor, so the current is proportional to frequency. In this Experiment, the value of Verf set by DAC module can control the current of inductor, as well as Vout=Vref; while $\mathrm{VDC}=20 \mathrm{~V}$, Ton $=5 \mathrm{us}$, the value of Verf is respectively $1.5 \mathrm{~V}$, $3 \mathrm{~V}, 4.5 \mathrm{~V}$, the switch frequency can be respectively calculated as $15 \mathrm{KHZ}, 30 \mathrm{KHZ}, 45 \mathrm{KHZ}$ through formula (5). The experimental results measured by Multisim oscilloscope are respectively $14.45 \mathrm{KHZ}, 29 \mathrm{KHZ}, 43.68 \mathrm{KHZ}$.

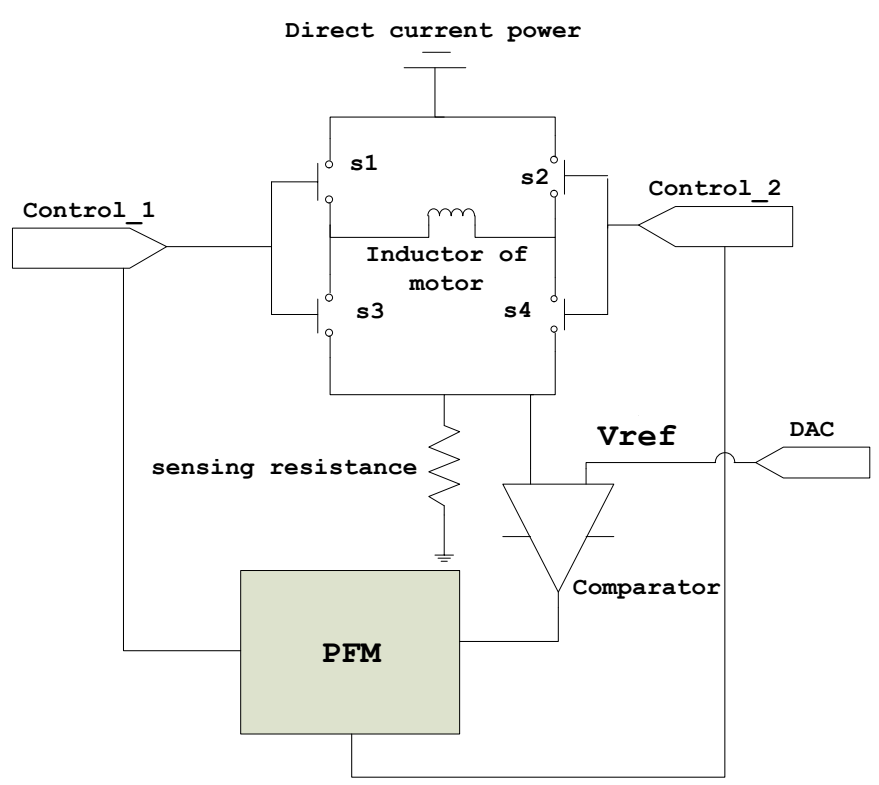

Fig. 3. PFM Motor Driver System Block Diagram. 


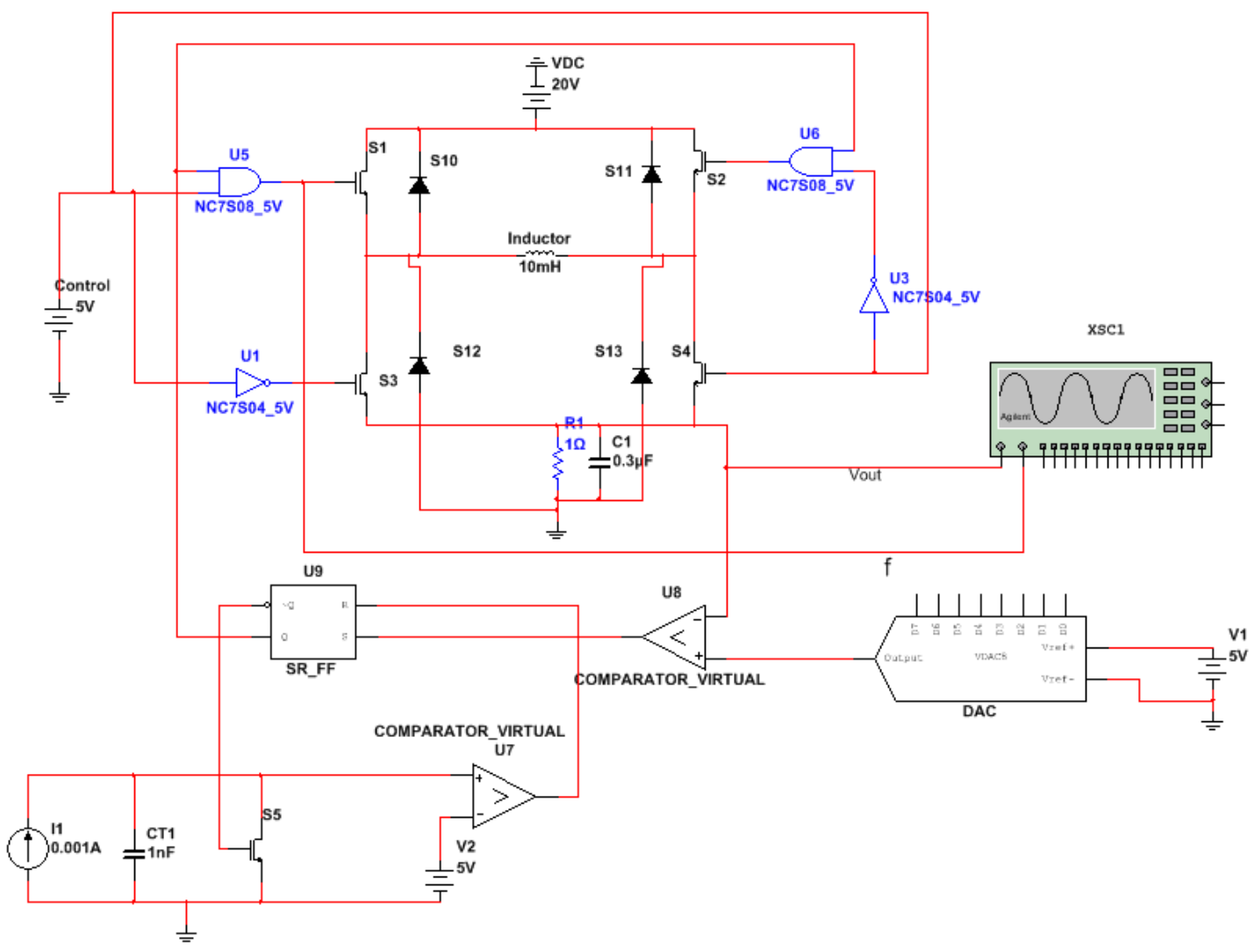

Fig. 4. PFM Motor Driver Circuit.

As shown in "Fig. 5" that is the oscilloscope sampling chart when Verf is set as $3 \mathrm{~V}$, we can see Vout $=3 \mathrm{~V} \pm 5 \mathrm{mV}$, current ripple is very small, the frequency is $29 \mathrm{KHZ}$. Thus, the motor current is proportional to the switching frequency, which achieves the desired effect of experiment.

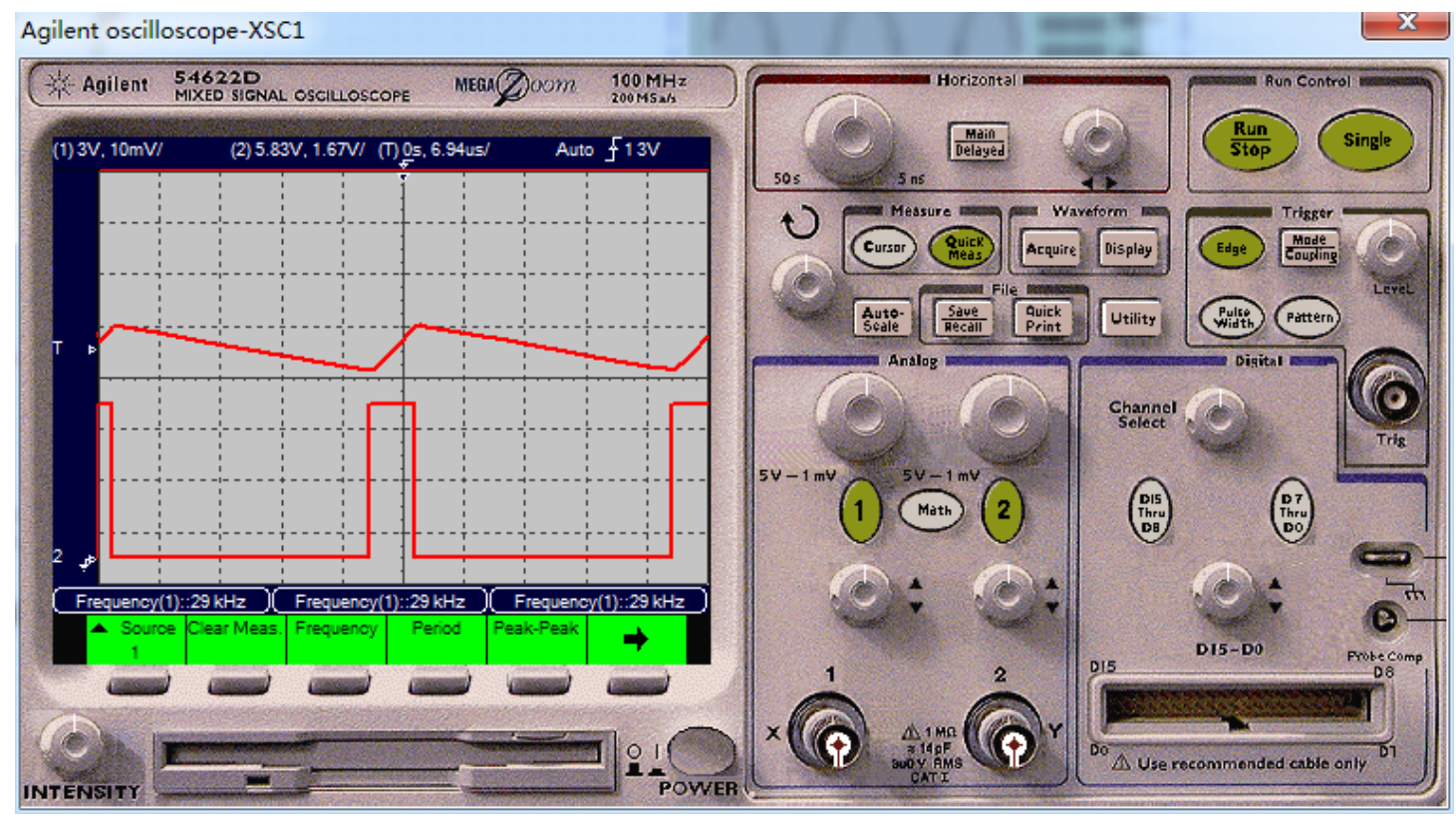

Fig. 5. Output Voltage and Switching waveform when Vref is 3V 
As mentioned above, we can use Multisim software to achieve gradually:

1. Through PWM (pulse width modulation) control buck type switching power supply circuit, combining digital characteristics of PWM with analog characteristics of power supply circuit.

2. Through PWM control motor current, combining digital characteristics of PWM and digital circuit with analog characteristics of motor current.

3. Through PFM control motor current, combining the digital-analog conversion characteristics of DAC and the digital characteristics of logic gates with the analog characteristics of motor current.

\section{HOW TO IMPROVE THE APPLICATION OF MULTISIM IN DIGITAL-ANALOG HYBRID CIRCUIT}

To sum up, in the teaching of digital-analog hybrid circuit, good teaching effect has been obtained through Multisim simulation platform. Firstly, the Multisim platform can help design digital-analog hybrid circuits conveniently, directly and quickly observe experiment results, and can easily modify the circuits according to experiment phenomenon, greatly saving debugging time. Secondly, there are a variety of virtual measuring instruments and common components in Multisim simulation platform, which can greatly reduce using of teaching tools and cost. Thirdly, compared with single digital circuit or analog circuit, the digital-analog hybrid circuit has more comprehensive and complexity. Since it is more time cost in hardware debugging, Multisim simulation platform can improve experiment efficiency and reduce debugging time that can be used to do more studies, as shown in this paper, also can improve innovation and comprehensive quality. Most importantly, through application of Multisim in hybrid circuit teaching, students had a deep understanding of distinctive characteristics and differences between analog circuit and digital circuit and improved hybrid circuit design ability. However, there are some disadvantages in hybrid circuit teaching using Multisim software. For example, experimental instruments and environment are in ideal state while actual instruments have errors and actual environment is changeable, all of which will cause error between simulation results and actual results. Therefore, in future, we should make better use of simulation software and take modifying error range of the simulation components to make it conform to actual value.

\section{CONCLUSION}

The Multisim software used in the digital-analog hybrid circuit by teachers may spread circuit knowledge and enhance innovation ability of students. Seen for it, the Multisim simulation platform has become a power support for the teaching of the digital-analog hybrid circuit, and the multisim is an efficient method applied in the teaching of the digitalanalog hybrid circuit. If corresponding measures are taken against possible problems and errors during the application, we believe that the teaching of the digital-analog hybrid circuit will achieve a benignant interaction with the Multisim software.

\section{REFERENCES}

[1] Zhou Yuanshen, Song Yongying, Wu Di. Power Electronics (Version III) [M]. Beijing: Machine Industry Press, 2016, pp. 315-316.

[2] Cai Huaixin, Li Hongfang, Liang Lifen, Chen Jiyao. Fundamentals of Physics (Version II) Book II [M]. Beijing: Higher Education Press, 2012, pp. 86-88.

[3] Chen Hanxiang, Wu Xiaomei. Power Electronics (Version II) [M]. Beijing: Science Press, 2010, pp. 148-151.

[4] Same with [1]

[5] Gleim G, Bertolini L, Heizmann F. Combined smart power IC for VCR with PWM controlled motor voltage[J]. IEEE Transactions on Consumer Electronics, 1994, 40(3): 377-386.

[6] Wang J, Bao B, Xu J, et al. Dynamical effects of equivalent series resistance of output capacitor in constant on-time controlled buck converter[J]. IEEE Transactions on Industrial Electronics, 2013, 60(5): $1759-1768$. 